\title{
Distribution of the Mycobacterium community and polycyclic aromatic hydrocarbons (PAHs) among different size fractions of a long-term PAH-contaminated soil
}

Maarten Uyttebroek, ${ }^{1}$ Philip Breugelmans, ${ }^{1}$ Mieke Janssen, ${ }^{1}$ Pierre Wattiau, ${ }^{2}$ Boris Joffe, ${ }^{3}$ Ulrich Karlson, ${ }^{4}$ Jose-Julio Ortega-Calvo, ${ }^{5}$ Leen Bastiaens, ${ }^{6}$ Annemie Ryngaert, ${ }^{6}$ Martina Hausner $^{3}$ and Dirk Springael ${ }^{1 *}$ ${ }^{1}$ Division Soil and Water Management, Catholic University of Leuven, Kasteelpark Arenberg 20, B-3001 Leuven, Belgium.

${ }^{2}$ Bacteriology and Immunology, Veterinary and Agrochemical Research Centre (VAR), Groeselenberg 99, B-1180 Brussels, Belgium.

${ }^{3}$ Lehrstuhl für Wassergute- und Abfallwirtschaft, Technische Universität München, Am Coulombwall, D85748 Garching, Germany.

${ }^{4}$ Environmental Chemistry and Microbiology, National Environmental Research Institute (NERI), Frederiksborgvej 399, PO Box 358, DK-4000 Roskilde, Denmark.

${ }^{5}$ Instituto de Recursos Naturales y Agrobiología, CSIC, Avenida Reina Mercedes 10, Apartado 1052, E-41080 Seville, Spain.

${ }^{6}$ Environmental and Process Technology, Flemish Institute for Technological Research (Vito), Boeretang 200, B-2400 Mol, Belgium.

\section{Summary}

Mycobacterium is often isolated from polycyclic aromatic hydrocarbon (PAH)-contaminated soil as degraders of PAHs. In model systems, Mycobacterium shows attachment to the PAH substrate source, which is considered to be a particular adaptation to low bioavailability as it results into increased substrate flux to the degraders. To examine whether PAHdegrading Mycobacterium in real PAH-contaminated soils, in analogy with model systems, are preferentially associated with PAH-enriched soil particles, the distribution of PAHs, of the PAH-mineralizing capacity and of Mycobacterium over different fractions of a soil

Received 28 April, 2005; accepted 4 November, 2005. *For correspondence. E-mail dirk.springael@biw.kuleuven.be; Tel. (+32) 16 321604; Fax (+32) 16321997. with an aged PAH contamination was investigated. The clay fraction contained the majority of the PAHs and showed immediate pyrene- and phenanthrenemineralizing activity upon addition of ${ }^{14} \mathrm{C}$-labelled pyrene or phenanthrene. In contrast, the sand and silt fractions showed a lag time of $15-26 h$ for phenanthrene and 3-6 days for pyrene mineralization. The maximum pyrene and phenanthrene mineralization rates of the clay fraction expressed per gram fraction were three to six times higher than those of the sand and silt fractions. Most-probable-number (MPN)-polymerase chain reaction demonstrated that Mycobacterium represented about $10 \%$ of the eubacteria in the clay fraction, while this was only about $0.1 \%$ in the sand and silt fractions, indicating accumulation of Mycobacterium in the PAH-enriched clay fraction. The Mycobacterium community composition in the clay fraction represented all dominant Mycobacterium populations of the bulk soil and included especially species related to Mycobacterium pyrenivorans, which was also recovered as one of the dominant species in the eubacterial communities of the bulk soil and the clay fraction. Moreover, Mycobacterium could be identified among the major culturable PAHdegrading populations in both the bulk soil and the clay fraction. The results demonstrate that PAHdegrading mycobacteria are mainly associated with the PAH-enriched clay fraction of the examined PAHcontaminated soil and hence, that also in the environmental setting of a PAH-contaminated soil, Mycobacterium might experience advantages connected to substrate source attachment.

Introduction

Polycyclic aromatic hydrocarbons (PAHs) form a class of toxic hydrophobic organic contaminants with a low bioavailability and a slow biodegradation in soil due to their low water solubility and high sorption to soil particles. Due to $\mathrm{PAH}$ ageing, long-term PAH-contaminated soils mostly contain only PAHs with low bioavailability. The PAHs are either strongly sorbed on the organic fraction of the soil or buried in pores inaccessible to microbes. Therefore, 
from a microbial perspective, $\mathrm{PAH}$-contaminated soils and in particular soils containing an aged $\mathrm{PAH}$ contamination can be considered oligotrophic (Wick et al., 2003a) and harsh environments for microbes to proliferate.

Bacterial strains isolated from PAH-contaminated soils for their ability to use PAHs as the sole source of carbon and energy belong to a limited number of taxonomic groups such as Sphingomonas, Burkholderia, Pseudomonas, Rhodococcus and Mycobacterium. Mycobacterium especially seems to be an important organism. It has often been reported to degrade high-molecular-weight (HMW) PAHs, i.e. PAHs with more than three rings such as pyrene and benzo[a]pyrene, with an extremely low water solubility (Kanaly and Harayama, 2000; Wick et al., 2001a). Moreover, recent reports on the physiology of $\mathrm{PAH}$-degrading Mycobacterium and on the ecology of $\mathrm{PAH}$-contaminated soils suggest that Mycobacterium is a specialist in proliferating in the oligotrophic environment of PAH-contaminated soil. Mycobacterium seems to be specialized in degrading sorbed $\mathrm{PAHs}$ as it has been preferentially selected from soils over other bacteria in enrichment systems with reduced bioavailable phenanthrene sorbed to model hydrophobic sorbents (Bastiaens et al., 2000; Friedrich et al., 2000; Grosser et al., 2000). In addition, Mycobacterium shows higher rates of mineralization of phenanthrene sorbed to hydrophobic polymers than expected from abiotic desorption rates (M. Uyttebroek and D. Springael, unpublished; Wells et al., 2005). Different reports indicate different physiological adaptations of Mycobacterium to oligotrophy and low PAH bioavailability. Mycobacterium frederiksbergense LB501T displays multiple substrate utilization (Wick et al., 2003a), low maintenance requirements (Wick et al., 2002) and a high specific affinity for anthracene (Wick et al., 2001b; 2002). Moreover, the LB501T strain attaches to and forms biofilms on anthracene crystals (Wick et al., 2002) and was found to attach to anthracene containing model sorbents (Wells et al., 2005). Attachment to the substrate source is thought to result in an efficient pollutant depletion at low concentrations at the cell surface, steeper concentration gradients and higher substrate transfer rates (Wick et al., 2001a), as such, optimizing substrate bioavailability. Also other Mycobacterium strains and $\mathrm{PAH}$ degraders from other bacterial genera have been reported to attach on the PAH substrate source (Stelmack et al., 1999; Bastiaens et al., 2000; Wattiau et al., 2002). Such features might play a role in the fitness and ecology of Mycobacterium in PAH-contaminated soils. Recently, it was found that Mycobacterium was present in relatively higher numbers in PAH-contaminated soils containing low concentrations of mainly HMW PAHs and low-bioavailable $\mathrm{PAHs}$ than in soils containing higher concentrations of mainly low-molecular-weight PAHs, i.e. PAHs with less than four rings such as phenanthrene (Leys et al., 2005).
Linking the physiological characteristics of $\mathrm{PAH}$ degrading bacteria regarding $\mathrm{PAH}$ degradation, such as substrate source attachment, studied in the laboratory to their ecology in historically $\mathrm{PAH}$-contaminated soils is of importance for interpreting the role of these features in the environmental habitat of these bacteria and the role of these bacteria in $\mathrm{PAH}$ bioattenuation in $\mathrm{PAH}$ contaminated soils. In this context, we studied the question whether or not in a PAH-contaminated soil, Mycobacterium is also associated with the $\mathrm{PAH}$ substrate source as observed in laboratory model systems. It was postulated that as in the lab model systems, attachment to the $\mathrm{PAH}$ substrate source might be an ecological advantage for PAH-degrading bacteria and therefore, contributes to their competence in the oligotrophic environment of a $\mathrm{PAH}$-contaminated soil. It would not only increase substrate flux as reported above but would also allow attached bacteria to be 'first' in line to take up the rare $\mathrm{PAH}$ substrate molecules desorbing from the soil.

To study this, a long-term PAH-contaminated soil was fractionated by low-energy sonication into four particlesize fractions and the distribution of the Mycobacterium community in the different fractions was examined and related to the $\mathrm{PAH}$ distribution and the $\mathrm{PAH}$-mineralizing capacity over the different soil fractions. The fractionation procedure was previously validated and applied to investigate enzyme activity in particle-size fractions (Stemmer et al., 1998) and for 16S rRNA-based community analysis in soil fractions (Kandeler et al., 2000; Sessitsch et al., 2001). The PAH-mineralizing capacity of the indigenous microbial community in the soil fractions was examined by mineralization experiments with ${ }^{14} \mathrm{C}$-phenanthrene and ${ }^{14} \mathrm{C}$-pyrene, while the proportion of Mycobacterium in the eubacterial community in the different soil fractions was estimated by most-probable-number (MPN)-polymerase chain reaction (PCR). Phenanthrene and pyrene degraders were estimated in the soil fractions by the WST-1 MPN method (Johnsen et al., 2002), based on growth on PAHs and Mycobacterium was identified in the enriched PAHdegrading communities by specific fluorescent in situ hybridization (FISH).

\section{Results and discussion}

\section{Physicochemical characteristics of soil fractions}

Based on dispersion with low-energy sonication (200 J per gram dry soil), the soil contained $11 \%$ clay (Table 1 ). The clay fraction had the highest content of total carbon $\left(97 \mathrm{~g} \mathrm{~kg}^{-1}\right)$ and total nitrogen $\left(6 \mathrm{~g} \mathrm{~kg}^{-1}\right)$ of all soil fractions. The $\mathrm{C} / \mathrm{N}$ ratio decreased from sand to silt to clay. An increasing $\mathrm{C}$ and $\mathrm{N}$ content and a decreasing $\mathrm{C} / \mathrm{N}$ ratio from coarse- to fine-sized soil fractions were also observed in several other studies (Jocteur Monrozier 
Table 1. Physicochemical characteristics of the examined bulk soil and the particle-size fractions.

\begin{tabular}{|c|c|c|c|c|c|c|c|}
\hline \multirow[b]{2}{*}{ Fraction $^{a}$} & \multirow[b]{2}{*}{$\begin{array}{l}\text { Particle-size } \\
\text { distribution (\%) }\end{array}$} & \multirow[b]{2}{*}{$\begin{array}{l}\text { Total C } \\
\left(\mathrm{g} \mathrm{kg}^{-1}\right)\end{array}$} & \multirow[b]{2}{*}{$\begin{array}{l}\text { Total N } \\
\left(\mathrm{g} \mathrm{kg}^{-1}\right)\end{array}$} & \multirow[b]{2}{*}{$\mathrm{C} / \mathrm{N}^{\mathrm{b}}$} & \multicolumn{3}{|c|}{ PAH concentration $\left(\mathrm{mg} \mathrm{kg}^{-1}\right)$} \\
\hline & & & & & $\mathrm{LMW}^{\mathrm{c}}$ & $\mathrm{HMW}^{\mathrm{d}}$ & Total \\
\hline Bulk soil & - & 31.2 & 1.3 & 25 & 4 & 88 & 92 \\
\hline Coarse sand & 37.4 & 23.8 & 0.4 & 63 & 1 & 18 & 19 \\
\hline Fine sand & 29.8 & 12.2 & 0.2 & 55 & 1 & 20 & 21 \\
\hline Silt & 18.7 & 35.5 & 1.2 & 30 & 4 & 84 & 88 \\
\hline Clay & 10.7 & 96.6 & 6.4 & 15 & 11 & 405 & 416 \\
\hline
\end{tabular}

a. Particle sizes: bulk soil $(<2 \mathrm{~mm})$; coarse sand $(2000-200 \mu \mathrm{m})$; fine sand $(200-53 \mu \mathrm{m})$; silt $(53-2 \mu \mathrm{m})$; clay $(2-0.1 \mu \mathrm{m})$.

b. Ratio of total $\mathrm{C}\left(\mathrm{g} \mathrm{kg}^{-1}\right)$ to total $\mathrm{N}\left(\mathrm{g} \mathrm{kg}^{-1}\right)$.

c. LMW: low-molecular-weight PAHs: less than four rings of 16 EPA-PAHs.

d. HMW: high-molecular-weight PAHs: more than three rings of 16 EPA-PAHs.

et al., 1991; Stemmer et al., 1998; 1999; Kandeler et al., 1999; Amellal et al., 2001a). The PAHs present in the bulk soil and in the fractions consisted almost exclusively (96\%) of HMW PAHs. Eighty-one per cent of the total PAH content in the bulk soil was recovered in the fractions. Clay contained the largest fraction $(49 \%)$ of the PAHs present in the bulk soil, compared with coarse sand, fine sand and silt that contained $8 \%, 7 \%$ and $18 \%$ of the PAHs respectively. This is in analogy with other reports where the fine silt fraction $(20-2 \mu \mathrm{m})$ and the clay fraction $(<2 \mu \mathrm{m})$ of $\mathrm{PAH}$-contaminated soils were found to contain a higher PAH concentration than the sand fraction (Amellal et al., 2001a,b; Krauss and Wilcke, 2002). The enrichment of the PAHs in the finer fractions of the soil can be explained by multiple reasons such as protection to biodegradation in microaggregates (Zweerts, 2005), the availability of a high specific surface for sorption, the high local nanoporosity for sequestration or the high content of hydrophobic organic matter (Xing and Pignatello, 1996; Chung and Alexander, 1998; 2002; Bogan and Sullivan, 2003). In our study, the high total $C$ content $\left(97 \mathrm{~g} \mathrm{~kg}^{-1}\right)$, which is related to the organic $\mathrm{C}$ content, in the clay fraction can most probably explain the accumulation of PAHs in this fraction as several studies have acknowledged the important role of organic $\mathrm{C}$ in PAH sequestration. On the other hand, $\mathrm{PAHs}$ are not always connected with the clay fraction as also the texture of the PAH-containing waste (ashes, slags, rubble) that was initially deposited in the soil is important for the PAH distribution among particle-size fractions (Krauss and Wilcke, 2002). In our study, the clay fraction clearly contained most of the PAHs. As a result, the clay fraction can be seen as the major environmental PAH substrate stock for potential PAH degraders in the examined $\mathrm{PAH}$-contaminated soil.

\section{Mineralization of ${ }^{14} \mathrm{C}$-phenanthrene and ${ }^{14} \mathrm{C}$-pyrene in soil fractions}

The mineralization of ${ }^{14} \mathrm{C}$-phenanthrene and ${ }^{14} \mathrm{C}$-pyrene to ${ }^{14} \mathrm{CO}_{2}$ in the bulk soil and the particle-size fractions was measured to examine the PAH-degrading capacity of the indigenous microbial community in the different soil fractions (Fig. 1). Obtained kinetic parameters are shown in Table 2. The relatively high final extent of mineralization (46-67\%) suggests the complete consumption of the ${ }^{14} \mathrm{C}$ PAHs, being the rest probably converted into biomass and biodegradation products different from $\mathrm{CO}_{2}$ (Garcia-Junco et al., 2003). The community in the clay fraction immediately initiated pyrene mineralization, while a lag phase of 3.5-5.9 days was observed before the communities in the silt and sand fractions started pyrene mineralization (Table 2). The mineralization of ${ }^{14} \mathrm{C}$-phenanthrene also started immediately in the clay fraction, while silt and sand showed a lag phase of 15-26 h. No significant difference

Table 2. Maximum mineralization rate and lag time for phenanthrene and pyrene mineralization by the indigenous microbial community in the bulk soil and the particle-size fractions.

\begin{tabular}{lllrr}
\hline & \multicolumn{2}{c}{ Maximum mineralization rate $\left(\% \mathrm{~h}^{-1}\right)$} & & \multicolumn{2}{c}{ Lag time $(\mathrm{h})$} \\
\cline { 2 - 3 } Fraction & Phenanthrene & Pyrene & Phenanthrene & Pyrene \\
\hline Bulk soil & $1.40 \mathrm{~B}$ & $1.05 \mathrm{AB}$ & $4.5 \mathrm{C}$ & $114.0 \mathrm{~B}$ \\
Coarse sand & $0.80 \mathrm{~B}$ & $0.35 \mathrm{C}$ & $25.5 \mathrm{~A}$ & $141.9 \mathrm{~A}$ \\
Fine sand & $0.95 \mathrm{~B}$ & $0.45 \mathrm{BC}$ & $22.7 \mathrm{AB}$ & $83.9 \mathrm{C}$ \\
Silt & $0.81 \mathrm{~B}$ & $0.35 \mathrm{C}$ & $14.7 \mathrm{~B}$ & $1.9 \mathrm{D}$ \\
Clay & $4.45 \mathrm{~A}$ & $1.54 \mathrm{~A}$ & $0.4 \mathrm{C}$ & \\
\hline
\end{tabular}

The results are the mean of three replicates. Means within one column with the same letter are not significantly different by a Tukey test $(P<0.05)$. 

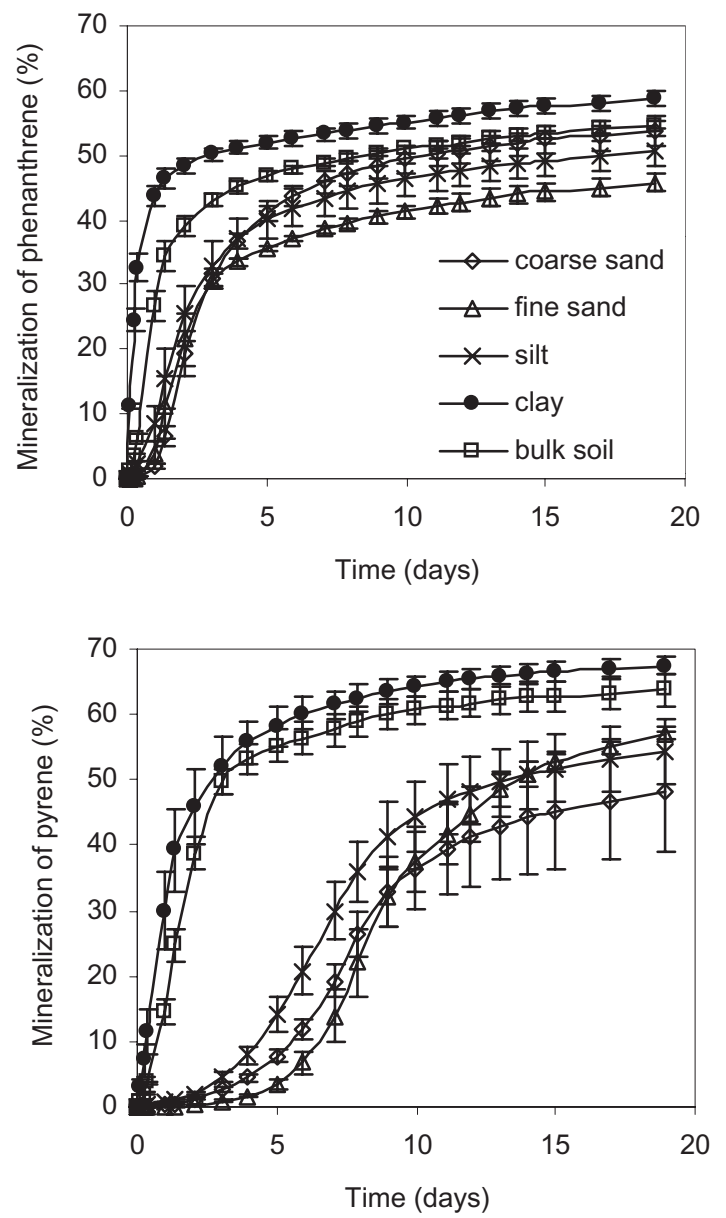

Fig. 1. Mineralization of ${ }^{14} \mathrm{C}$-phenanthrene and ${ }^{14} \mathrm{C}$-pyrene $\left(\right.$ as $\left.{ }^{14} \mathrm{CO}_{2}\right)$ by the indigenous microbial community in the bulk soil and the particle-size fractions. Error bars represent standard errors from three replicates.

in lag time of phenanthrene and pyrene mineralization was observed between clay and the bulk soil. The maximum mineralization rate of phenanthrene and pyrene was significantly different for the clay and sand-silt communities (Table 2). First of all, these results show that despite the aged nature of the PAH contamination in the used soil, the soil contained and sustained a highly active PAHdegrading community. Similar results have been obtained with other PAH-contaminated soils (Johnsen and Karlson, 2006). Although freshly added PAHs do not behave in the same way in soil as aged PAHs (Hatzinger and Alexander, 1995; Carmichael et al., 1997; Alexander, 2000) and therefore, the relative fast mineralization of the freshly added ${ }^{14} \mathrm{C}$-labelled PAHs cannot be extrapolated to degradation of native PAHs in the soil, it might indicate that in nature desorbing degradable $\mathrm{PAH}$ compounds are rapidly degraded by the residing community. Second, we show that the PAH-mineralizing activity in the soil was especially associated with the clay fraction. It shows that the used fractionation procedure retained the PAHmineralizing activity of the bulk soil in the soil fractions and that different $\mathrm{PAH}$-mineralizing activities calculated per gram fraction exist between them. The mineralization curves for the sand and silt fractions were sigmoidal in nature, which indicated that a period of growth of PAHdegrading organisms was needed before significant mineralization of the added ${ }^{14} \mathrm{C}$-PAHs occurred (Grosser et al., 1995; MacLeod and Semple, 2002). In contrast, direct mineralization was observed for the clay fraction, indicating that the clay fraction contained higher numbers of PAH mineralizing populations than the other fractions. This accounted especially for pyrene mineralizing populations. Our data show that the PAH-degrading capacity is localized in the clay fraction of the PAH-contaminated soil and is therefore connected with the PAH substrate source. As $\mathrm{PAH}$-degrading bacterial isolates able to use pyrene as sole source of carbon and energy are almost exclusively Mycobacterium, the high pyrene-degrading capacity observed in the clay fraction, is a first indication of the presence of high numbers of PAH-mineralizing Mycobacterium in the PAH-containing clay fraction.

\section{MPN-PCR estimate of Mycobacterium in soil fractions}

A Mycobacterium-specific nested PCR (Leys et al., 2005) was applied as a MPN-PCR to estimate the number of Mycobacterium cells within the eubacterial community in the different soil fractions (Fig. 2). The use of a MPN-PCR approach to enumerate bacterial populations in soil is prone to errors and is therefore not an absolute quantifi-

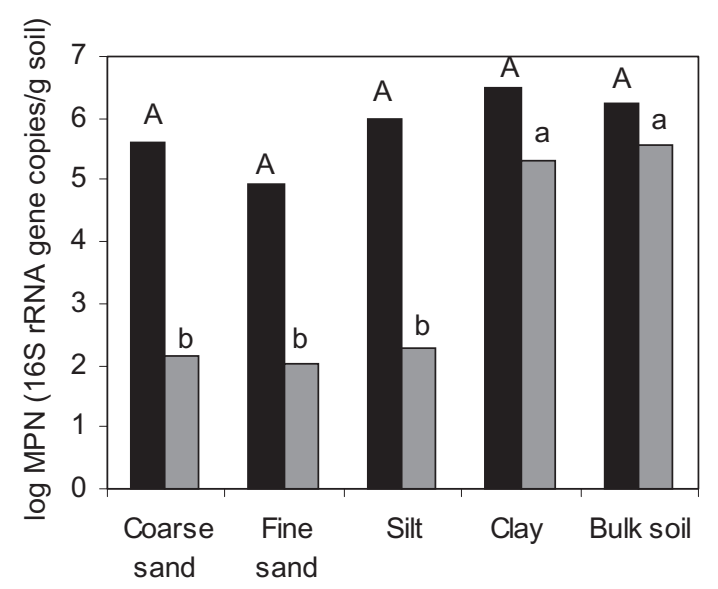

- Eubacteria $\square$ Mycobacterium

Fig. 2. Most-probable-number (MPN)-PCR estimate of the $16 \mathrm{~S}$ rRNA gene copy number of eubacteria and Mycobacterium for the bulk soil and the particle-size fractions. Means of log MPN (two replicates) with a different uppercase or lowercase letter are significantly different by a Tukey test $(P<0.05)$ for eubacteria or Mycobacterium respectively. 


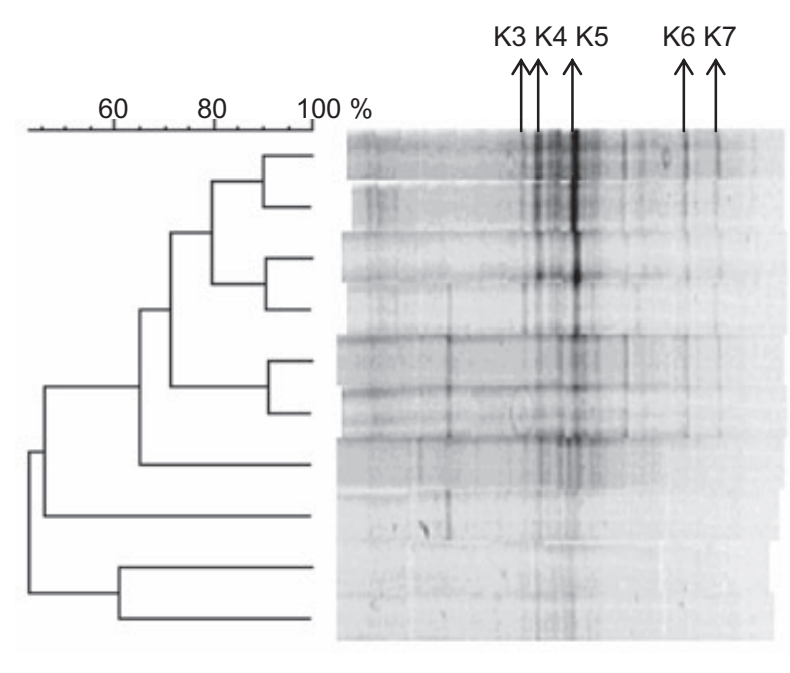

Fig. 3. UPGMA dendrogram of $16 \mathrm{~S}$ rRNAbased PCR-DGGE community profiles of eubacteria in the different soil fractions of the examined PAH-contaminated soil. Replicates of soil fractionation are indicated by $\mathrm{A}$ and $\mathrm{B}$. Soil DNA, used as template for PCR amplification, was diluted 10 -fold. The scale indicates the similarity level $(0-100 \%)$. cation (Fredslund et al., 2001). However, the numbers provided for Mycobacterium and eubacteria are indicative for the relative proportions of both bacterial groups in the different soil fractions. The eubacterial log MPN count (as an estimate of the eubacterial 16S rRNA gene copies per gram soil) for the clay fraction was 6.5. No significant difference in eubacterial MPN count between clay and the other fractions was found. The log MPN count for Mycobacterium (as an estimate of the Mycobacterium 16S rRNA gene copies per gram soil) in the clay fraction was 5.3. This log MPN was significantly different from sand and silt fractions, but not from the bulk soil. The number of $16 \mathrm{~S}$ rRNA gene copies in prokaryotic genomes can vary from one to 15 copies (Klappenbach et al., 2001), while Mycobacterium has one to two copies (Bercovier et al., 1986; Leys et al., 2005). The eubacterial communities in the bulk soil and the different soil fractions seem to be dominated by $\alpha$-proteobacteria and actinomycetes (see below) which both have an average rRNA gene copy number of two (Klappenbach et al., 2001). Hence, assuming an average 16S rRNA gene copy number for the eubacterial and Mycobacterium community of two, mycobacteria represented about $10 \%$ of the eubacteria in the clay fraction, while this was only about $0.1 \%$ in the sand and silt fractions. These results showed that the Mycobacterium community present in the bulk soil was proportionally more concentrated in the clay fraction of the examined $\mathrm{PAH}$-contaminated soil than in the other fractions.

\section{Community analysis of indigenous eubacteria and Mycobacterium in soil fractions}

The unweighted pair group method using arithmetic averages (UPGMA) dendrogram of the eubacterial community of the bulk soil and the particle-size fractions is shown in Fig. 3. The eubacterial community structure within the soil clearly depended on the particle-size fraction. The eubacterial community of the clay fraction was different from sand and silt fractions and represented the dominant soil community with a similarity [ \pm standard deviation (SD)] between the bulk soil and clay of $80 \pm 1 \%$. The dominant populations in the bulk soil and clay fraction were identified by sequencing relevant $16 \mathrm{~S}$ rRNA gene bands in the denaturant gradient gel electrophoresis (DGGE) profile (Fig. 3) and analysis of the sequences. The outcome of the analysis is shown in Table 3 and shows that the dom-

Table 3. Closest GenBank match and sequence similarity of selected 16S rRNA gene-based DGGE bands.

\begin{tabular}{llll}
\hline Band $^{\text {a }}$ & Accession No. & Closest GenBank match (accession No.) & Similarity (\%) \\
\hline K3 & AM085778 & Bradyrhizobium sp. BTA-1 (AJ558025) & 98.4 \\
K4 & AM085779 & Porphyrobacter tepidarius DSM10594 (AF465839) & 97.9 \\
K5 & AM085780 & Uncultured $\alpha$-proteobacterium clone 406T3 (DQ110117) & 95.6 \\
K6 & AM085781 & Arthrobacter sp. M4 (AY177360) & 99.5 \\
K7 & AM085782 & Mycobacterium pyrenivorans DSM44605 (AJ431371) & 99.0 \\
K10 & AM085785 & Mycobacterium pyrenivorans DSM44605 (AJ431371) & 98.8 \\
K11 & AM085786 & Mycobacterium tusciae JS617 (AF498655) & 98.8 \\
K12 & AM085787 & Mycobacterium tusciae Fl-25796 (AF058299) & 98.8 \\
K13 & AM085788 & Mycobacterium tusciae JS617 (AF498655) & 98.8 \\
\hline
\end{tabular}

a. Bands K3-K7: PCR of the 16S rRNA gene with eubacterial primers GC40-63f and 518r; bands K10-K13: PCR of the 16S rRNA gene with Mycobacterium-specific primers MYCO66f and GC40-MYCO600r. 


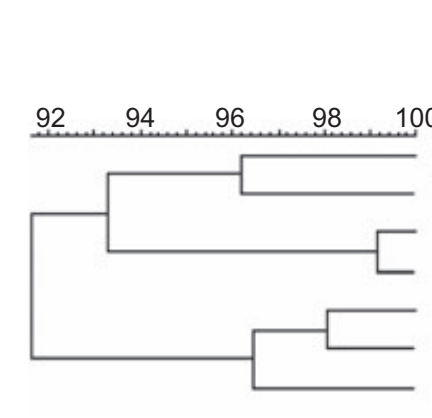

K10 K11 K12 K13

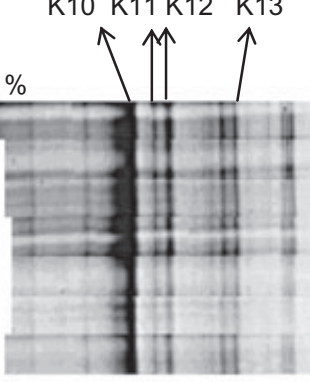

inant bacterial species in the soil and the clay fraction were related to species such as an uncultured $\alpha$ proteobacterium (band K5), Bradyrhizobium (band K3), Porphyrobacter (band K4), Arthrobacter (band K6) and Mycobacterium pyrenivorans (band K7). It shows that next to Mycobacterium, also other bacteria are concentrated in the clay fraction. This was not unexpected; several studies have indicated that microbial biomass concentrates in the silt and clay fractions of a soil (Jocteur Monrozier et al., 1991; Van Gestel et al., 1996; Stemmer et al., 1998; Kandeler et al., 2000; Sessitsch et al., 2001) as organic matter and clay particles provide substrates and nutrients for the survival of bacteria (Van Gestel et al., 1996). Interestingly, M. pyrenivorans is a recently described $\mathrm{PAH}$ degrading Mycobacterium species that can use pyrene as sole source of carbon and energy (Derz et al., 2004). Moreover, M. pyrenivorans was also identified as the dominant Mycobacterium population within the Mycobacterium community (band K10) (Table 3). The dendrogram of the Mycobacterium community showed a high similarity ( \pm SD) of $92 \pm 3 \%$ between the bulk soil and clay (Fig. 4). The DGGE fingerprints of the Mycobacterium community in the sand and silt fractions showed a weak signal and were therefore excluded from the dendrogram. All other bands within the Mycobacterium community (K11-K13) corresponded to 16S rRNA gene sequences of Mycobacterium tusciae. Interestingly, mycobacteria related to M. tusciae have also been found in different other longterm $\mathrm{PAH}$-contaminated soils using culture-independent techniques (Leys et al., 2005). In contrast, up to now, mycobacteria related to $M$. tusciae have never been cultured as PAH degrader from soils. This can possibly be explained by the slow growth (4 weeks) of M.tusciae in currently used culture media (Tortoli et al., 1999).

\section{Most-probable-number estimate of culturable $\mathrm{PAH}$ degraders in soil and Mycobacterium identification by $\mathrm{FISH}$}

To link community structure and functionality of Mycobacterium in soil K3663, the number of phenanthrene and pyrene degraders in the soil fractions were estimated by the WST-1 MPN method and the presence of Mycobacte-
Fig. 4. UPGMA dendrogram of $16 \mathrm{~S}$ rRNAbased PCR-DGGE community profiles of Mycobacterium spp. in the examined PAH-contaminated bulk soil and its clay fraction. Replicates of soil fractionation are indicated by $A$ and B. Soil DNA, used as template for PCR amplification, was diluted 10 -fold (indicated by 1 ) or 100 -fold (indicated by 2). The scale indicates the similarity level $(0-100 \%)$. bulk soil B2

clay B2 rium among the culturable $\mathrm{PAH}$-degrading bacteria was examined by FISH. The log MPN count of the PAH degraders (per gram soil) in the clay fraction was 7.5 for phenanthrene and 6.6 for pyrene. These log MPN counts were significantly higher than those of the sand and silt fractions, but were similar to those of the bulk soil (Fig. 5). The amount of pyrene degraders in fine sand was lower than the detection limit of $10^{2}$ cells per gram soil. Therefore, log MPN of pyrene degraders for fine sand were excluded from the Tukey test. The log MPN count for phenanthrene degraders in the clay fraction was 1 log unit higher than the amount of eubacteria in the clay fraction, as estimated with MPN-PCR. As mentioned above, MPNPCR does not give absolute numbers and can underestimate the actual size considerably due to factors such as DNA extraction efficiency and PCR efficiency (Fredslund et al., 2001). On the other hand, also the WST-1 MPN method probably underestimates the numbers of $\mathrm{PAH}$ degraders by detecting only those cells able to grow in liquid culture with phenanthrene or pyrene as sole source of carbon and energy. In addition, the MPN method does

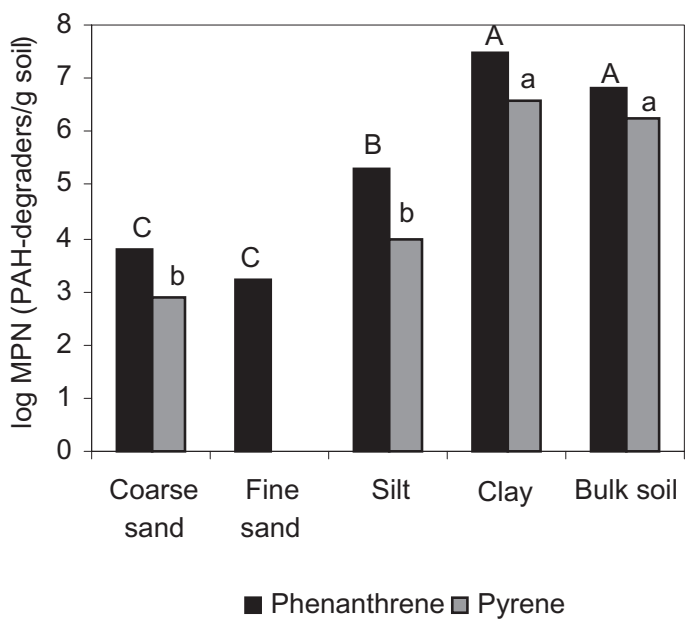

Fig. 5. Most-probable-number (MPN) estimate of phenanthrene and pyrene degraders for the bulk soil and the particle-size fractions. Means of log MPN (two replicates) with a different uppercase or lowercase letter are significantly different by a Tukey test $(P<0.05)$ for phenanthrene or pyrene degraders respectively. 
not take into account co-metabolism of PAHs. This underestimation was demonstrated by the existence of a ${ }^{14} \mathrm{C}$ pyrene mineralization capacity in the fine sand fraction, while no pyrene utilizers were found in this fraction by the MPN count, as is in accordance with similar results of Johnsen and Karlson (2006).

The PAH degraders in the MPN microplates were examined for the presence of Mycobacterium by peptide nucleic acid (PNA)-FISH, using specific probes for Mycobacterium species related to either Mycobacterium austroafricanum, M. frederiksbergense or M. gilvum (Table 4). These three Mycobacterium spp. are known to include most of the described PAH-degrading Mycobacterium strains (Leys et al., 2005). rRNA gene sequence analysis assigned M.pyrenivorans to the 16S rRNA gene subgroup that contains also M. austroafricanum (Derz et al., 2004). Moreover, the sequence of the PNA probe specific for M. austroafricanum matched completely with the $16 S$ rRNA sequence of the type strain of M.pyrenivorans and hence the PNA probe will also target $M$. pyrenivorans. Mycobacterium tusciae is not a target of these FISH probes. Mycobacterium austroafricanum/ M. pyrenivorans-related species proved to be important phenanthrene-degrading populations in silt $(48 \%$ of all phenanthrene-degrading cells) and clay (17\% of all phenanthrene-degrading cells). This indicates that M. pyrenivorans recovered as most dominant Mycobacterium population on the basis of $16 \mathrm{~S}$ rRNA gene analysis (see above) is also a dominant phenanthrene-degrading population in the soil and the clay fraction. Mycobacterium frederiksbergense was recognized as an important pyrene-degrading population in the clay fraction (24\% of all pyrene-degrading cells). No cells in the microplates were identified as M.gilvum. The observation that $M$. frederiksbergense was present among the culturable $\mathrm{PAH}$ degraders is in contrast with the data from the $16 \mathrm{~S}$ rRNA gene analysis of the Mycobacterium community in which $M$. frederiksbergense was not present. We were not able to recover all Mycobacterium bands from the Mycobacterium DGGE fingerprints as clones suitable for sequencing and it might be that the bands missing among the clones represented $M$. frederiksbergense. Alterna- tively, as found for other PAH-contaminated soils, using a PCR approach specifically targeting $M$. frederiksbergense, $M$. frederiksbergense might be present at concentrations in the soil which were too low for becoming a visible dominant population on the Mycobacterium 16S rRNA gene DGGE profile (N.M. Leys and D. Springael, unpublished). Reports indicate that populations proportionally present at $1 \%$ and less might be missed by the PCR-DGGE approach (Muyzer et al., 1993). Mycobacterium-specific FISH identified only $19-43 \%$ of the culturable PAH-utilizing cells in the bulk soil and the clay fraction as Mycobacterium spp. The other $\mathrm{PAH}$-degrading cells might belong to other species of Mycobacterium. Unfortunately, a FISH probe directed towards other Mycobacterium species or towards the complete Mycobacterium genus is not available. Alternatively, members of other bacterial genera might have been present among the $\mathrm{PAH}$ degraders in the wells. Indeed, next to Mycobacterium, other bacterial genera have been described to degrade and grow on phenanthrene. In contrast, bacteria able to utilize pyrene are almost exclusively Mycobacterium. Finally, bacteria not able to attack PAHs but metabolically associated with $\mathrm{PAH}$-degrading bacteria in food webs might have developed in the wells. Also the highly similar eubacterial community DGGE fingerprints of the clay fraction and the bulk soil show that other types of bacteria different from Mycobacterium occupy the PAH-enriched clay fraction. The pyrene degraders in the coarse sand and silt fractions could not be identified by $\mathrm{FISH}$, as sufficient cells for identification by FISH could not be recovered from the pyrene-coated wells. This is in analogy with the PAH-degrading activity measurements where pyrene degradation in the sand and silt fractions was only observed after lag phases of 3-6 days. These results show that the Mycobacterium populations that accumulated in the $\mathrm{PAH}$-enriched clay fraction consist at least partially of $\mathrm{PAH}$ degraders.

\section{Conclusions}

Our results show that in the examined long-term $\mathrm{PAH}$ contaminated soil, PAH-degrading Mycobacterium,

Table 4. Identification of phenanthrene and pyrene degraders by Mycobacterium-specific FISH.

\begin{tabular}{|c|c|c|c|c|c|c|c|}
\hline \multirow[b]{2}{*}{ FISH probes ${ }^{a}$} & \multicolumn{5}{|c|}{ Phenanthrene $(\%)^{b}$} & \multicolumn{2}{|c|}{ Pyrene $(\%)^{b}$} \\
\hline & Bulk soil & Coarse sand & Fine sand & Silt & Clay & Bulk soil & Clay \\
\hline Mycobacterium austroafricanum & 42 & 3 & 0 & 48 & 17 & 6 & 9 \\
\hline Mycobacterium frederiksbergense & 1 & 0 & 0 & 6 & 2 & 25 & 24 \\
\hline
\end{tabular}

a. Probe for Mycobacterium gilvum gave no positive results.

b. The identification of PAH degraders is expressed as a relative percentage of Mycobacterium cells (visualized by specific FISH) to eubacterial cells (visualized by DAPI). No sufficient sample could be prepared for pyrene degraders in coarse sand and silt; no pyrene degraders in fine sand. The pyrene numbers for bulk soil and clay are for one of the two replicates; no sufficient sample could be prepared for the other replicate. 
among other bacteria, was clearly associated with the clay fraction that formed the main storage fraction of PAHs in the soil. Mycobacterium represented about $10 \%$ of the eubacteria in the clay fraction, while this was only about $0.1 \%$ in the sand and silt fractions, showing that the Mycobacterium community present in the bulk soil was proportionally more concentrated in the clay fraction of the examined PAH-contaminated soil than in the other fractions. Moreover, Mycobacterium was among the main pyrene- and phenanthrene-utilizing populations in the soil, and a high pyrene mineralization activity, an activity almost exclusively associated with $\mathrm{PAH}$-degrading $\mathrm{Myco}$ bacterium isolates, was registered in the clay fraction. The association of Mycobacterium with the $\mathrm{PAH}$-containing soil fraction suggests attachment of Mycobacterium to $\mathrm{PAH}$-containing soil particles and seems to be in analogy with attachment and biofilm formation of Mycobacterium on PAH crystals and model sorbents (Bastiaens et al., 2000; Wick et al., 2002; Wells et al., 2005). The association of bacteria with organic pollutant contaminated clay particles has been shown before. Lünsdorf and colleagues (2000) reported on the appearance of aggregates consisting of bacteria surrounded by polychlorinated biphenyl (PCB)-containing clay leaflets in an artificial setup. As proposed for attachment/biofilm formation of Mycobacterium on $\mathrm{PAH}$ crystals and $\mathrm{PAH}$-containing model sorbents, PAH-degrading Mycobacterium might be benefiting from this situation by increasing $\mathrm{PAH}$ substrate flux and hence PAH bioavailability (Wick et al., 2001a). In addition, Mycobacterium cells may also have direct access to slow-desorbing PAH compounds (Wells et al., 2005). Moreover, this fraction provides other food sources (from organic carbon) and nutrients (Kandeler et al., 2000; Sessitsch et al., 2001) which might be of importance to remain active and competitive in the oligotrophic environment (Wick et al., 2003a). However, the question remains whether the association of Mycobacterium with $\mathrm{PAH}-$ containing substrata in soil is simply due to the fact: (i) that clay is a preferential habitat for Mycobacterium or (ii) that the specific enrichment of Mycobacterium in the clay fraction of the examined soil is the consequence of a food strategy specifically directed to PAHs. Regarding the first explanation, Mycobacterium displays a hydrophobic cell wall that might result into association with organic loaded clay particles (Wick et al., 2003a) or Mycobacterium cells may be better protected from protozoa in the clay fraction (Sessitsch et al., 2001). Similarly, Mycobacterium has been shown to have low oxygen requirements (Fritzsche, 1994) and clay particles might be a better niche for such organisms. Indeed, Sessitsch and colleagues (2001) showed that clay particles provided a niche for aerobes as well as for anaerobes, whereas larger particle sizes were dominated by aerobic bacteria. Not much research has been performed on the distribution of Mycobacterium in different soil fractions in non-contaminated soils. Sessitsch and colleagues (2001) showed that actinomycetes belonged to the main populations of the clay fraction of an agricultural soil. However, no data on other soil fractions or on relative proportions of actinomycetes to all bacteria were provided. Regarding the second explanation, we recently showed that sliding over a surface by a $\mathrm{PAH}$-degrading Mycobacterium strain was strongly increased by distant phenanthrene crystals suggesting $\mathrm{PAH}$-directed motility of Mycobacterium, even in the presence of low concentrations of the PAH (L. Nielsen and D. Springael, unpublished). As such, upon contamination of the soil and concentration of the PAHs in the clay fraction, Mycobacterium might have been attracted by the $\mathrm{PAH}$ food source and build up a population in the clay fraction. Other characteristics of Mycobacterium such as high hydrophobicity, low oxygen requirements and multiple substrate utilization might then have been additional advantageous characteristics to compete well with other bacteria at that location for nutrients and even PAHs. Moreover, it was found that Mycobacterium adapts its surface depending on the growth substrate. Growth on PAHs supported adhesion to hydrophobic surfaces (including PAHs) yet not glass surfaces (Wick et al., 2002; 2003b).

To differentiate between both explanations, more research is needed applying a similar microscale analysis to other $\mathrm{PAH}$-contaminated and non-contaminated soils. In particular, non-contaminated soils and soils with the $\mathrm{PAH}$ contamination concentrated on larger particle-size fractions would be of interest. Krauss and Wilcke (2002) observed a heterogeneous distribution of PAHs among the particle-size fractions of urban soils because the soils received different $\mathrm{PAH}$-contaminated wastes with varying texture, but no research was performed on the microbial ecology of the soils. Interestingly, Amellal and colleagues (2001a) showed that indigenous PAH-degrading bacteria were embedded in the aggregates of the fine silt fraction (20-2 $\mu \mathrm{m})$, containing most of the PAHs. However, these bacteria were not identified.

Whatever the explanation is, the association of Mycobacterium with $\mathrm{PAH}$-containing soil particles might be of importance for natural bioattenuation activities in soil as slowly desorbing $\mathrm{PAH}$ molecules might be directly degraded by the nearby $\mathrm{PAH}$-degrading biocatalysts and as such leaching of PAHs might be minimized. Indeed, despite the low amounts of PAHs, presented in a lowbioavailable form in the examined soil, the microbial community in the soil still showed high PAH-mineralization activity for both pyrene and phenanthrene indicating that those populations are ready to degrade desorbing $\mathrm{PAH}$ molecules. The fact that, despite these apparently nonselective conditions, a high $\mathrm{PAH}$-degrading population survives and remains active with a high number of $\mathrm{Myco-}$ 
844 M. Uyttebroek et al.

bacterium concentrated around the PAH substrate source is on itself an intriguing study object.

\section{Experimental procedures}

\section{Soil sample}

Soil sample K3663 was taken from a historically PAH-contaminated site of a former coal gasification plant in Denmark. The soil was sieved at $2 \mathrm{~mm}$ and stored fresh for 4 months at $4^{\circ} \mathrm{C}$ in the dark. Selected physicochemical characteristics of the soil are shown in Table 1. Total carbon and total nitrogen content were measured using a combustion analyser (Vario MAX CN, Elementar Analysensysteme GmbH, Hanau, Germany). The PAH content 16 PAHs listed by the US Environmental Protection Agency (EPA) was measured as described by Leys and colleagues (2005). Soil pH of K3663 was 7.6, as determined in $\mathrm{CaCl}_{2} 10^{-2} \mathrm{M}$ (soil/liquid ratio of $1: 2.5)$.

\section{Fractionation procedure}

Fractionation of the soil was performed according to the method described by Stemmer and colleagues (1998). Lowenergy sonication (200 J per gram soil) of the soil sample in combination with wet sieving and repeated centrifugation resulted into four particle-size fractions, i.e. 2000-200 $\mu \mathrm{m}$ (coarse sand); 200-53 $\mu \mathrm{m}$ (fine sand); 53-2 $\mu \mathrm{m}$ (silt) and 2$0.1 \mu \mathrm{m}$ (clay). The fractions were kept overnight at $4^{\circ} \mathrm{C}$ before use.

\section{${ }^{14} \mathrm{C}$ - $\mathrm{PAH}$ mineralization by indigenous soil bacteria}

Mineralization of $\left[9-{ }^{14} \mathrm{C}\right]$-phenanthrene (Sigma, $13.1 \mathrm{mCi}$ $\mathrm{mmol}^{-1}$, dissolved in dichloromethane, radiochemical purity $>98 \%$ ) or $\left[4,5,9,10-{ }^{14} \mathrm{C}\right]$-pyrene (Sigma, $55 \mathrm{mCi} \mathrm{mmol}^{-1}$, dissolved in acetone, radiochemical purity $>98 \%$ ) by the indigenous microbial community in the bulk soil and the different soil fractions was examined in $15 \mathrm{ml}$ Pyrex tubes. After evaporation of dichloromethane or acetone (100-150 $\mu \mathrm{l}$ ) in $250 \mathrm{ml}$ Erlenmeyer flasks, the ${ }^{14} \mathrm{C}-\mathrm{PAHs}$ were dissolved in minimal mineralization medium ( $\mathrm{pH}$ 5.7) (Ortega-Calvo et al., 1995) to have a final radioactivity of $0.007 \mu \mathrm{Ci} \mathrm{ml}^{-1}$. The PAH concentration in the mineralization medium was below water solubility, $1.18 \mathrm{mg} \mathrm{l}^{-1}$ for phenanthrene or $0.135 \mathrm{mg} \mathrm{l}^{-1}$ for pyrene at $25^{\circ} \mathrm{C}$ (Miller et al., 1985). Unlabelled PAH was not added. PAH-containing mineralization medium $(5 \mathrm{ml})$ was added to $200 \mathrm{mg}$ (dry weight) of soil. The tubes were closed with Teflon-lined stoppers equipped with alkali traps $(1 \mathrm{ml}$ of $0.5 \mathrm{M} \mathrm{NaOH}$ ) to measure ${ }^{14} \mathrm{CO}_{2}$ produced from ${ }^{14} \mathrm{C}-\mathrm{PAHs}$ and incubated at $20^{\circ} \mathrm{C}$ on a rotary shaker at 100 r.p.m. Periodically, the $\mathrm{NaOH}$ solution was removed from the trap and replaced with fresh alkali. The removed $\mathrm{NaOH}$ solution was mixed with $5 \mathrm{ml}$ of liquid scintillation cocktail (Ready Safe, Beckman Instruments) and the mixture was kept in darkness for at least $8 \mathrm{~h}$ for dissipation of chemiluminescence. Radioactivity was measured with a liquid scintillation counter (model LS6500; Beckman Instruments, Fullerton, CA, USA).
Cumulative mineralization curves were established in triplicate for the bulk soil and each soil fraction. The maximum mineralization rate $\left(\% \mathrm{~h}^{-1}\right)$ was calculated as the slope of the linear regression line between two successive points of the mineralization curve where the amount of ${ }^{14} \mathrm{CO}_{2}$ showed the largest increase. The lag time was calculated as the intersection of the $x$-axis with the linear regression line of maximum mineralization (Broos et al., 2005).

\section{DNA extraction}

Total DNA was extracted from the bulk soil and the soil fractions by a method modified from Boon and colleagues (2000). For each soil fraction, $0.4 \mathrm{~g}$ of soil material, $0.6 \mathrm{~g}$ of beads $(0.10-0.11 \mathrm{~mm}$ diameter) (B. Braun Biotech International, Melsungen, Germany) and $0.8 \mathrm{ml}$ of $0.1 \mathrm{M} \mathrm{Na}_{3} \mathrm{PO}_{4}$ $(\mathrm{pH} 8)$ were added together in each of three $2 \mathrm{ml}$ microtubes (Greiner Bio-One). The mixtures were beaten for $45 \mathrm{~s}$ at speed 6.0 using a Hybaid RiboLyser (Thermo Electron). A lysozyme solution (32 $\mu \mathrm{l})\left(50 \mathrm{mg} \mathrm{ml}^{-1}\right.$ Tris- $\mathrm{HCl}, 10 \mathrm{mM}, \mathrm{pH}$ 9) was added, followed by $30 \mathrm{~min}$ head-over-end shaking at $20^{\circ} \mathrm{C}$. Subsequently, $60 \mu \mathrm{l}$ of $20 \%$ SDS and $0.2 \mathrm{ml}$ of $8 \mathrm{M}$ ammonium acetate $(\mathrm{pH} \mathrm{7.2)}$ were added, followed by $10 \mathrm{~min}$ head-over-end shaking at $20^{\circ} \mathrm{C}$. The supernatant of the three microtubes was collected after centrifugation at $5916 \mathrm{~g}$ for $15 \mathrm{~min}$ at $15^{\circ} \mathrm{C}$ in a $10 \mathrm{ml}$ tube (Novolab, Geraardsbergen, Belgium), resulting in a final DNA extract from $1.2 \mathrm{~g}$ of soil. After purification with $2.4 \mathrm{ml}$ of chloroform-isoamylalcohol $(24: 1)$, the mixture was shaken for $60 \mathrm{~min}$ head-over-end at $20^{\circ} \mathrm{C}$ and centrifuged at $5916 \mathrm{~g}$ for $15 \mathrm{~min}$ at $15^{\circ} \mathrm{C}$. The aqueous phase was transferred to a new tube and 0.8 volume of isopropanol was added for overnight precipitation of the DNA at $-20^{\circ} \mathrm{C}$. After centrifugation at $12074 \mathrm{~g}$ for $30 \mathrm{~min}$ at $15^{\circ} \mathrm{C}$, the pellet was dried at room temperature for $1 \mathrm{~h}$ and resuspended in $250 \mu$ of TE buffer (10 mM Tris; $1 \mathrm{mM}$ EDTA; $\mathrm{pH}$ 8). The crude DNA extract was purified with the Wizard $^{\circledR}$ DNA clean-up kit with vacuum manifold (Promega), as described by Promega. The purified DNA was finally recovered in $50 \mu \mathrm{l}$ of TE buffer and stored at $-20^{\circ} \mathrm{C}$.

\section{Polymerase chain reaction amplification}

Eubacterial 16S rRNA gene fragments were amplified by PCR using the eubacterial primers GC40-63f and 518r (El Fantroussi et al., 1999), as described by Moreels and colleagues (2004). Mycobacterium 16S rRNA gene fragments were amplified by PCR using the direct or nested PCR approach with Mycobacterium-specific primers MYCO66f and GC40-MYCO600r, as described by Leys and colleagues (2005). In the nested PCR approach, the eubacterial primers $27 f$ and $1492 r$ were used in the first PCR and $1 \mu \mathrm{l}$ of the resulting $P C R$ product was used as template in the second PCR with the MYCO66f and GC40-MYCO600r primers. Polymerase chain reaction amplification was performed on an Eppendorf Mastercycler. The PCR mixture contained $1 \mu \mathrm{l}$ of soil DNA as template, 1.25 U Taq polymerase (Qiagen), $25 \mathrm{pmol}$ of each primer (Qiagen), $10 \mathrm{nmol}$ of each dNTP (Invitrogen) and $1 \times$ PCR buffer (Qiagen) in a total volume of $50 \mu \mathrm{l}$. 
Most-probable-number (MPN)-PCR estimate of eubacterial and Mycobacterium populations in soil

The MPN-PCR enumeration was adapted from Fredslund and colleagues (2001). DNA was extracted from the different soil fractions after fractionation in duplicate. A 10-fold dilution series of the soil DNA extract (to $10^{-6}$ ) was prepared in TE buffer and three times $1 \mu \mathrm{l}$ of each dilution was used as template in the Mycobacterium-nested PCR described above (three-row MPN). The MPN enumeration of eubacteria was based on the PCR products of the first PCR and MPN enumeration of Mycobacterium was based on the PCR products of the second PCR. The PCR products were run at $90 \mathrm{~V}$ for $1.25 \mathrm{~h}$ in $1.5 \%$ agarose gels (Electro-4 Gel Tank, Hybaid Limited, Ashford, UK), containing $0.2 \mathrm{mg} \mathrm{l}^{-1}$ ethidiumbromide and photographed on a UV transillumination table with a gel documentation system (Vilber Lourmat, Cedex, France). The numbers of positive and negative tubes that produced amplification products were scored for each sample. The MPN was calculated by using Microsoft Excel, as described by Briones and Reichardt (1999), and is an estimation of the 16S rRNA gene copy number of eubacteria or Mycobacterium in the soil fractions (Fredslund et al., 2001).

\section{Denaturant gradient gel electrophoresis analysis}

Denaturant gradient gel electrophoresis was performed on an INGENYphorU-2 system (Ingeny International, Goes, the Netherlands). Denaturant gradient gel electrophoresis analysis of the PCR products from amplification with the eubacterial primers GC40-63 $f$ and $518 r$ was performed as described by Moreels and colleagues (2004), but for $15 \mathrm{~h}$ at $120 \mathrm{~V}$. Denaturant gradient gel electrophoresis analysis of the Mycobacterium PCR products was performed as described by Leys and colleagues (2005). Denaturant gradient gel electrophoresis gels were stained for $30 \mathrm{~min}$ with $1 \times$ SYBR Gold (Molecular Probes, Leiden, the Netherlands) and photographed on a UV transillumination table with a GeneLink camera system (SYNGENE, Cambridge, UK). GelCompar II software 3.5 (Applied Maths, Sint-MartensLatem, Belgium) was used for cluster analysis of DGGE fingerprints. The similarity matrix for the fingerprints was calculated based on the Pearson product-moment correlation coefficient (Pearson, 1926) and the UPGMA (Sneath and Sokal, 1973) was used as clustering algorithm to calculate the dendrogram. The SD of a dendrogram branch was obtained by reconstructing the similarity values from the branch and comparing the values with the original similarity values.

\section{Sequence analysis of DGGE bands}

Bands from eubacterial and Mycobacterium 16S rRNA gene-based DGGE profiles were excised from the DGGE gel and DNA, eluted at $4^{\circ} \mathrm{C}$ with $100 \mu$ of PCR water (Cambrex) for $4 \mathrm{~h}$, was used as template for PCR amplification with the appropriate primers as described above. The PCR products were cloned into the plasmid vector $\mathrm{pCR}^{{ }^{\circledR}} 2.1$ TOPO $^{\circledR}$, using the TOPO TA Cloning kit (Invitrogen, Merelbeke, Belgium) as described by Invitrogen. To analyse transformants with eubacterial insert, a nested PCR was performed on the clones including a first PCR with M13f and M13r primers as described by Invitrogen and a second PCR with eubacterial primers GC40-63f and $518 \mathrm{r}$ on the products of the first PCR as described above. To analyse transformants with Mycobacterium insert, PCR was performed on the clones with Mycobacterium-specific primers MYCO66f and GC40-MYCO600r as described above, but with an initial denaturation step for $10 \mathrm{~min}$ at $94^{\circ} \mathrm{C}$. Denaturant gradient gel electrophoresis patterns of cloned fragments were compared with the appropriate fingerprints of the soil eubacterial or Mycobacterium community and appropriate clones were chosen for sequence analysis. Polymerase chain reaction products obtained from the clones were purified with the PCR purification kit (Qiagen) as described by Qiagen and subjected to sequencing reactions. Sequencing reactions were performed with the QuickStart DNA sequencing kit (Beckman) using the eubacterial 16S rRNA gene primer 530r (Lane, 1991) and analysed on an automatic sequencer (CEQ ${ }^{\mathrm{TM}} 8000$, Beckman Coulter, Fullerton, CA, USA). Resulting partial 16S rRNA gene sequences (about $400 \mathrm{bp}$ ) were compared with sequences deposited in GenBank by performing a BLASTN search (Altschul et al., 1997).

\section{Nucleotide sequence accession number}

The partial 16S rRNA gene sequence data have been submitted to the EMBL database under Accession No. AM085778 to AM085782 and Accession No. AM085785 to AM085788.

Most-probable-number (MPN) estimate of PAH-degrading bacteria in soil and Mycobacterium identification by FISH

The MPN enumeration of phenanthrene and pyrene degraders in the different soil fractions was based on the detection of microbial growth on phenanthrene or pyrene in microtitre plates by using the respiration indicator WST-1, as described by Johnsen and colleagues (2002). The MPN enumeration for the different soil fractions was performed after fractionation in duplicate. Bacterial pellets of 10 positive wells of the highest dilutions, resulting from growth on phenanthrene or pyrene, were pooled to have sufficient cells for FISH analysis. Mycobacterium-specific FISH analysis was performed by using fluorescently labelled PNA probes (with sequence in parentheses) targeting the 16S rRNA of M. austroafricanum (5'-TCTAGGCACGTCCT-3'), M. frederiksbergense (5'-GCATGGTCATATTC-3') and M. gilvum (5'-ATGCGGTCCTATTC-3'). These probes were specially designed for detection of these three Mycobacterium spp. in environmental samples and the applied hybridization conditions will be described elsewhere (B. Joffe and M. Hausner, unpublished). The identification of phenanthrene and pyrene degraders in Table 4 is expressed as a relative percentage of Mycobacterium cells (visualized by specific FISH) to eubacterial cells (visualized by DAPI: 4',6-diamidino-2-phenylindole). Bacterial cells were counted in duplicate as an average of 10 microscopic view fields, each containing at least 400 bacterial cells. 


\section{Statistical analysis}

The Tukey test $\left(\mathrm{SAS}^{\circledR}\right.$ 9.1; Cary, NC, USA) $(P<0.05)$ was used for all statistical comparisons of maximum mineralization rate, lag time and log transformed MPN.

\section{Acknowledgements}

This study was financially supported by a grant from the Research Fund of the K.U.Leuven to M.U. and by the European Commission Project QLRT-1999-00326. We thank M. Van Hessche for assistance in the sequence analysis, $Q$. Simons for assistance in the PAH measurements, L. Frederiksen for the MPN enumeration of PAH degraders, M. Bueno-Montes for assistance in the ${ }^{14} \mathrm{C}-\mathrm{PAH}$ experiments, $\mathrm{S}$. Schioetz-Hansen for providing soil samples, A. Sessitsch for advice on the soil fractionation procedure and L. Wick for useful comments.

\section{References}

Alexander, M. (2000) Aging, bioavailability, and overestimation of risk from environmental pollutants. Environ Sci Technol 34: 4259-4265.

Altschul, S.F., Madden, T.L., Schäffer, A.A., Zhang, J., Zhang, Z., Miller, W., and Lipman, D.J. (1997) Gapped BLAST and PSI-BLAST: a new generation of protein database search programs. Nucleic Acids Res 25: 3389-3402.

Amellal, N., Portal, J.-M., Vogel, T., and Berthelin, J. (2001a) Distribution and location of polycyclic aromatic hydrocarbons (PAHs) and PAH-degrading bacteria within polluted soil aggregates. Biodegradation 12: 49-57.

Amellal, N., Portal, J.-M., and Berthelin, J. (2001b) Effect of soil structure on the bioavailability of polycyclic aromatic hydrocarbons within aggregates of a contaminated soil. Appl Geochem 16: 1611-1619.

Bastiaens, L., Springael, D., Wattiau, P., Harms, H., deWachter, R., Verachtert, H., and Diels, L. (2000) Isolation of adherent polycyclic aromatic hydrocarbon (PAH)-degrading bacteria using $\mathrm{PAH}$-sorbing carriers. Appl Environ Microbiol 66: 1834-1843.

Bercovier, H., Kafri, O., and Sela, S. (1986) Mycobacteria possess a surprisingly small number of ribosomal RNA genes in relation to the size of their genome. Biochem Biophys Res Commun 136: 1136-1141.

Bogan, B.W., and Sullivan, W.R. (2003) Physicochemical soil parameters affecting sequestration and mycobacterial biodegradation of polycyclic aromatic hydrocarbons in soil. Chemosphere 52: 1717-1726.

Boon, N., Goris, J., De Vos, P., Verstraete, W., and Top, E.M. (2000) Bioaugmentation of activated sludge by an indigenous 3-chloroaniline-degrading Comamonas testosteroni strain I2gfp. Appl Environ Microbiol 66: 2906-2913.

Briones, A.M., Jr, and Reichardt, W. (1999) Estimating microbial population counts by 'most probable number' using Microsoft Excel ${ }^{\circledR}$. J Microbiol Methods 35: 157-161.

Broos, K., Mertens, J., and Smolders, E. (2005) Toxicity of heavy metals in soil assessed with various soil microbial and plant growth assays: a comparative study. Environ Toxicol Chem 24: 634-640.
Carmichael, L.M., Christman, R.F., and Pfaender, F.K. (1997) Desorption and mineralization kinetics of phenanthrene and chrysene in contaminated soils. Environ Sci Technol 31: 126-132.

Chung, N., and Alexander, M. (1998) Differences in sequestration and bioavailability of organic compounds aged in dissimilar soils. Environ Sci Technol 32: 855-860.

Chung, N., and Alexander, M. (2002) Effect of soil properties on bioavailability and extractability of phenanthrene and atrazine sequestered in soil. Chemosphere 48: 109-115.

Derz, K., Klinner, U., Schuphan, I., Stackebrandt, E., and Kroppenstedt, R.M. (2004) Mycobacterium pyrenivorans sp. nov., a novel polycyclic-aromatic-hydrocarbon-degrading species. Int J Syst Evol Microbiol 54: 2313-2317.

El Fantroussi, S., Verschuere, L., Verstraete, W., and Top, E.M. (1999) Effect of phenylurea herbicides on soil microbial communities estimated by analysis of 16S rRNA gene fingerprints and community-level physiological profiles. Appl Environ Microbiol 65: 982-988.

Fredslund, L., Ekelund, F., Jacobsen, C.S., and Johnsen, K. (2001) Development and application of a most-probablenumber-PCR assay to quantify flagellate populations in soil samples. Appl Environ Microbiol 67: 1613-1618.

Friedrich, M., Grosser, R.J., Kern, E.A., Inskeep, W.P., and Ward, D.M. (2000) Effect of model sorptive phases on phenanthrene biodegradation: molecular analysis of enrichments and isolates suggests selection based on bioavailability. Appl Environ Microbiol 66: 2703-2710.

Fritzsche, C. (1994) Degradation of pyrene at low defined oxygen concentrations by a Mycobacterium sp. Appl Environ Microbiol 60: 1687-1689.

Garcia-Junco, M., Gomez-Lahoz, C., Niqui-Arroyo, J.-L., and Ortega-Calvo, J.-J. (2003) Biosurfactant- and biodegradation-enhanced partitioning of polycyclic aromatic hydrocarbons from nonaqueous-phase liquids. Environ Sci Technol 37: 2988-2996.

Grosser, R.J., Warshawsky, D., and Vestal, R.J. (1995) Mineralization of polycyclic and $n$-heterocyclic aromatic compounds in hydrocarbon-contaminated soils. Environ Toxicol Chem 14: 375-382.

Grosser, R.J., Friedrich, M., Ward, D.M., and Inskeep, W.P. (2000) Effect of model sorptive phases on phenanthrene biodegradation: different enrichment conditions influence bioavailability and selection of phenanthrene-degrading isolates. Appl Environ Microbiol 66: 2695-2702.

Hatzinger, P.B., and Alexander, M. (1995) Effect of aging of chemicals in soil on their biodegradability and extractability. Environ Sci Technol 29: 537-545.

Jocteur Monrozier, L., Ladd, J.N., Fitzpatrick, R.W., Foster, R.C., and Raupach, M. (1991) Components and microbial biomass content of size fractions in soils of contrasting aggregation. Geoderma 49: 37-62.

Johnsen, A.R., and Karlson, U. (2006) PAH degradation capacity of soil microbial communities - does it depend on $\mathrm{PAH}$ exposure? Microb Ecol (in press). DOI:10.1007/ s00248-005-0022-5.

Johnsen, A.R., Bendixen, K., and Karlson, U. (2002) Detection of microbial growth on polycyclic aromatic hydrocarbons in microtiter plates by using the respiration indicator WST-1. Appl Environ Microbiol 68: 2683-2689.

Kanaly, R.A., and Harayama, S. (2000) Biodegradation of 
high-molecular-weight polycyclic aromatic hydrocarbons by bacteria. J Bacteriol 182: 2059-2067.

Kandeler, E., Stemmer, M., and Klimanek, E.-M. (1999) Response of soil microbial biomass, urease and xylanase within particle size fractions to long-term soil management. Soil Biol Biochem 31: 261-273.

Kandeler, E., Tscherko, D., Bruce, K.D., Stemmer, M., Hobbs, P.J., Bardgett, R.D., and Amelung, W. (2000) Structure and function of the soil microbial community in microhabitats of a heavy metal polluted soil. Biol Fertil Soils 32: 390-400.

Klappenbach, J.A., Saxman, P.R., Cole, J.R., and Schmidt, T.M. (2001) Rrndb: the ribosomal RNA operon copy number database. Nucleic Acids Res 29: 181-184.

Krauss, M., and Wilcke, W. (2002) Sorption strength of persistent organic pollutants in particle-size fractions of urban soils. Soil Sci Soc Am J 66: 430-437.

Lane, D.J. (1991) 16S/23S rRNA sequencing. In Nucleic Acid Techniques in Bacterial Systematics. Stackebrandt, E., and Goodfellow, M. (eds). Chichester, UK: John Wiley \& Sons, pp. 115-175.

Leys, N.M., Ryngaert, A., Bastiaens, L., Wattiau, P., Top, E.M., Verstraete, W., and Springael, D. (2005) Occurrence and community composition of fast-growing Mycobacterium in soils contaminated with polycyclic aromatic hydrocarbons. FEMS Microbiol Ecol 51: 375-388.

Lünsdorf, H., Erb, R.W., Abraham, W.-R., and Timmis, K.N. (2000) 'Clay hutches': a novel interaction between bacteria and clay minerals. Environ Microbiol 2: 161-168.

MacLeod, C.J.A., and Semple, K.T. (2002) The adaptation of two similar soils to pyrene catabolism. Environ Pollut 119: 357-364.

Miller, M.M., Wasik, S.P., Huang, G.-L., Shiu, W.-Y., and Mackay, D. (1985) Relationships between octanol-water partition coefficient and aqueous solubility. Environ Sci Technol 19: 522-529.

Moreels, D., Bastiaens, L., Ollevier, F., Merckx, R., Diels, L., and Springael, D. (2004) Evaluation of the intrinsic methyl tert-butyl ether (MTBE) biodegradation potential of hydrocarbon contaminated subsurface soils in batch microcosm systems. FEMS Microbiol Ecol 49: 121-128.

Muyzer, G., de Waal, E.C., and Uitterlinden, A.G. (1993) Profiling of complex microbial populations by denaturing gradient gel electrophoresis analysis of polymerase chain reaction-amplified genes coding for $16 \mathrm{~S}$ rRNA. Appl Environ Microbiol 59: 695-700.

Ortega-Calvo, J.-J., Birman, I., and Alexander, M. (1995) Effect of varying the rate of repartitioning of phenanthrene in nonaqueous-phase liquids on biodegradation in soil slurries. Environ Sci Technol 29: 2222-2225.

Pearson, K. (1926) On the coefficient of radical likeliness. Biometrika 18: 105-117.

Sessitsch, A., Weilharter, A., Gerzabek, M.H., Kirchmann, H., and Kandeler, E. (2001) Microbial population structures in soil particle size fractions of a long-term fertilizer field experiment. Appl Environ Microbiol 67: 4215-4224.

Sneath, P.H.H., and Sokal, R.R. (1973) Numerical Taxonomy: The Principles and Practice of Numerical Classification. San Francisco, CA, USA: W.H. Freeman.
Stelmack, P.L., Gray, M.R., and Pickard, M.A. (1999) Bacterial adhesion to soil contaminants in the presence of surfactants. Appl Environ Microbiol 65: 163-168.

Stemmer, M., Gerzabek, M.H., and Kandeler, E. (1998) Organic matter and enzyme activity in particle-size fractions of soils obtained after low-energy sonication. Soil Biol Biochem 30: 9-17.

Stemmer, M., Von Lützow, M., Kandeler, E., Pichlmayer, F., and Gerzabek, M.H. (1999) The effect of maize straw placement on mineralization of $\mathrm{C}$ and $\mathrm{N}$ in soil particle size fractions. Eur J Soil Sci 50: 73-85.

Tortoli, E., Kroppenstedt, R.M., Bartoloni, A., Caroli, G., Jan, I., Pawlowski, J., and Emler, S. (1999) Mycobacterium tusciae sp. nov. Int J Syst Bacteriol 49: 1839-1844.

Van Gestel, M., Merckx, R., and Vlassak, K. (1996) Spatial distribution of microbial biomass in microaggregates of a silty-loam soil and the relation with the resistance of microorganisms to soil drying. Soil Biol Biochem 28: 503510.

Wattiau, P., Springael, D., Agathos, S.N., and Wuertz, S. (2002) Use of the pAL5000 replicon in PAH-degrading mycobacteria: application for strain labelling and promoter probing. Appl Microbiol Biotechnol 59: 700-705.

Wells, M., Wick, L.Y., and Harms, H. (2005) Model polymer release system study of $\mathrm{PAH}$ bioaccessibility: the relationship between rapid release and bioaccessibility. Environ Sci Technol 39: 1055-1063.

Wick, L.Y., Springael, D., and Harms, H. (2001a) Bacterial strategies to improve the bioavailability of hydrophobic organic pollutants. In Treatment of Contaminated Soil: Fundamentals, Analysis, Applications. Stegmann, R., Brunner, G., Calmano, W., and Matz, G. (eds). Heidelberg, Germany: Springer-Verlag, pp. 203-217.

Wick, L.Y., Colangelo, T., and Harms, H. (2001b) Kinetics of mass transfer-limited bacterial growth on solid PAHs. Environ Sci Technol 35: 354-361.

Wick, L.Y., Ruiz de Munain, A., Springael, D., and Harms, H. (2002) Responses of Mycobacterium sp. LB501T to the low bioavailability of solid anthracene. Appl Microbiol Biotechnol 58: 378-385.

Wick, L.Y., Pasche, N., Bernasconi, S.M., Pelz, O., and Harms, H. (2003a) Characterization of multiple-substrate utilization by anthracene-degrading Mycobacterium frederiksbergense LB501T. Appl Environ Microbiol 69: 61336142.

Wick, L.Y., Pelz, O., Bernasconi, S.M., Andersen, N., and Harms, H. (2003b) Influence of the growth substrate on ester-linked phospho- and glycolipid fatty acids of PAHdegrading Mycobacterium sp. LB501T. Environ Microbiol 5: 672-680.

Xing, B., and Pignatello, J.J. (1996) Time-dependent isotherm shape of organic compounds in soil organic matter: implication for sorption mechanisms. Environ Toxicol Chem 15: 1282-1288.

Zweerts, H. (2005) Ageing, biodegradation and composition of polycyclic aromatic hydrocarbons and mineral oil in soils. PhD Thesis. Leuven, Belgium: Catholic University of Leuven. 